Revista Iberoamericana, Vol. LXXIV, Núm. 222, Enero-Marzo 2008, 1-

\title{
IMPREDECIBLE OFICIO EL DE LA MARAVILLA: ENTREVISTA AL ESCRITOR PUERTORRIQUEÑO PEDRO CABIYA
}

POR

NÉSTOR E. RODRÍGUEZ

University of Toronto

La literatura del Caribe hispano insular de las últimas décadas, sobre todo a partir de los años 90, evidencia un marcado anhelo aperturista en términos estéticos que da cuenta de incómodos posicionamientos ante el establishment cultural de Puerto Rico, Cuba y República Dominicana. En el caso específico de Puerto Rico, la narrativa de Pedro Cabiya (1971) es uno de los estadios más notables de esos nuevos derroteros del decir literario antillano. Pedro Cabiya se inició como escritor a principios de los 90 publicando cuentos en las principales revistas y suplementos literarios puertorriqueños, así como en antologías como La cervantiada (1993) y El rostro y la máscara (1995). Es autor de las colecciones de cuentos Historias tremendas (1999) e Historias atroces (2003), y de la novela gráfica Ánima Sola (2004). Esta conversación comenzó la mañana del 23 abril de 2006 en la autopista Duarte, a las afueras de Santo Domingo, y terminó en Sosúa, en la costa norte de la República Dominicana.

NÉStor Rodríguez: Desde tus primeros textos publicados a principios de los 90 en San Juan es posible atisbar un proyecto estético distinto con respecto al de buena parte de la literatura precedente; hablo de esa narrativa que asumió la tarea de representar los contornos de "lo puertorriqueño" como su carta de naturaleza.

Pedro Cabiya: Esa marca tan forzada y obvia de lo "puertorriqueño" que desde temprano detecté en la literatura que nos daban a leer en la escuela me sacaba de quicio, me repugnaba, me inspiraba un rechazo visceral. No soporté nunca las novelas de Enrique Laguerre, de Emilio Díaz Valcárcel; el costumbrismo bobo de Abelardo Díaz Alfaro; el talante pesimista de Pedro Juan Soto, ni las deprimentes historias de René Marqués. Sé que estoy mezclando generaciones, pero, en gran medida, a todas estas obras las atraviesa una misma tendencia a la desgracia, a la tragedia, a la derrota. Cuando no se trata de regodeos lastimeros que "retratan" nuestra enferma sociedad, son celebraciones autocongratulatorias del callejonismo, de nuestra innegable debilidad por los usos del caserío y el vacilón de esquina. Pero no eran realmente estos contenidos los que me inspiraban repudio; era el uso falso que de ellos hace esa literatura, forzándolos a servir un propósito político, comunitario, de identidad. Hasta pedagógico, diría; estampas, moralejas. Son obras que tienen más que ver con un proyecto social que con una propuesta literaria, artística. Recuerdo que desde temprano, mi deseo era, precisamente, encontrar en los autores nacionales una propuesta 
artística, que me regalaran una posible literatura de la imaginación. Pero pronto descubrí que no existía ni un solo personaje atractivo en la literatura puertorriqueña, ninguna saga de valor, ningún villano realmente despreciable, ningún héroe al que quisiéramos parecernos o cuya muerte realmente nos doliera... Y ¿ no se trata la literatura de conseguir eso? Digo, por lo menos así entiendo yo mi oficio. Pero era todo tan normal, tan desabrido... ¿Para qué leer? No existía una manera innovadora, literaria, de presentar esos temas, de refundirlos, de hacerlos mitología. El problema con esos escritores, creo, era que estaban empeñados en decir la Verdad, olvidando que la literatura es un oficio de mentirosos, de embaucadores. El escritor es un ser básicamente infantil, incluso cuando narra las peripecias más desgarradoras: ahí está Milan Kundera, Haruki Murakami o Margaret Atwood para comprobarlo. Lo mismo pasa con el humor: presento a Patrick Chamoiseau como evidencia. Los escritores de los cuarenta y cincuenta no querían reírse de nada, y los de los sesenta y setenta lo cogieron todo a relajo. Unos se lamentaron, los otros se burlaron, pero ninguno se imaginó una buena historia. Recuerdo haber tenido muy claro todo lo que acabo de expresarte ya para la edad de once años, cuando empecé a escribir mis primeros cuentos. Llegó un momento en que empecé a relacionar la literatura puertorriqueña con la escuela; cosas que uno tenía que leer para contestar exámenes... Pero lo más sorprendente era que, a mi alrededor, yo no podía dejar de oír narraciones increíbles. No de los libros, sino de mi familia, de mis amigos, de las familias de mis amigos. Primos que se enamoran y mueren desbarrancados; luces que persiguen a la gente en la montaña; un platillo volador que derribó un poste de luz en Levittown; ${ }^{1}$ la visita que le hizo Satanás a una devota tía; cómo se salvó uno de los mecánicos del taller de mi tío, agonizando en su lecho, cuando mataron al perro que había secuestrado su alma; la historia de ese perro que no era perro, sino la reencarnación de una antigua querida del mecánico; etcétera. Aprendí el oficio de la maravilla, del asombro, con la gente, no con libros, y ciertamente no con libros puertorriqueños. Percibí de inmediato que el que cuenta una historia la siente muy pequeña, al principio, y luego la siente crecer en el regodeo de mentir, de exagerar, de embellecer, y de hacerlo de manera que uno está hablando en serio. Por otro lado, la televisión y los videojuegos eran otra fuente inagotable de inspiración. Las animaciones japonesas y los manga todavía hoy forman parte de mi acervo literario. Muchas veces, cuando termino de escribir un cuento, me percato de que he utilizado una estructura de etapas y "bosses” copiada de los videojuegos, a su vez, claro, copiada de la estructura mitológica del héroe... Cuando entré en la universidad me di a conocer con un cuento titulado "La madre", que ganó el primer premio del legendario Certamen Literario de Estudios Generales. ${ }^{2}$ Una peripecia que define el tipo de escritor que nunca podré dejar de ser: un joven sale en busca de una prostituta. Se lleva a una vieja, por pena y vergüenza, pero en medio del acto sexual, termina engullido por la vagina de la mujer. El joven, ahora un bebé indefenso, llora desconsolado antes de ser absorbido por completo. Ese es el tipo de cuento que me gusta hacer, aún hoy día. Tenía dieciocho años entonces. Escribí

\footnotetext{
${ }^{1}$ Levittown integra el municipio de Toa Baja, que limita con el de San Juan al noreste de Puerto Rico.

${ }^{2}$ Famoso certamen literario auspiciado por la facultad de Estudios Generales de la Universidad de Puerto Rico (Río Piedras). Luis Rafael Sánchez y Ana Lydia Vega lo han obtenido en el pasado. El jurado que premió a Cabiya en 1990 estuvo integrado por Kalman Barsy, Emilio Díaz Valcárcel, Juan Antonio Ramos y Lilliana Ramos Collado.
} 
obligado por la idea de lo que yo quería que ocurriera en el cuento, no por presiones de deber social o para ofrecer moralejas patrióticas. Y esa ha sido mi única brújula desde entonces hasta hoy.

NR: Tus visiones en torno a la literatura se han visto matizadas por enconadas polémicas, especialmente en el entorno de la Universidad de Puerto Rico. Recuerdo por ejemplo tus diferencias públicas con Mayra Santos Febres en cuanto al universalismo y la literatura puertorriqueña.

PC: Por supuesto, la UPR tiene una gran historia de subversión, política, social y discursiva. La UPR fue mi centro de operaciones durante cinco años. Era inevitable que la literatura que yo estaba haciendo chillara en ciertos conciliábulos. Y de esos había muchos. Imbéciles desfasados que llamaban la atención por los pasillos, y que a veces escribían cosas provocadoras. La idea era esa, chocar, llamar la atención. Pero una vez que tenían mi atención, no había nada que ver, sino tristeza y más de lo mismo. De modo que muchas veces fui tildado de vendepatria, de clasista, de snob, de elitista, bla bla bla. Esta pugna tomó auge y fue mejor articulada con esa discusión que Mayra y yo tuvimos en los medios impresos. Ella hablaba de que la literatura debía ensalzar lo particular, lo que nos hace únicos; la misma cantaleta de la identidad. Recuerdo que mencionó a un par de escritores africanos que estaban haciendo eso mismo, para que siguiéramos su ejemplo. El problema era que esos escritores que ella mencionó eran totales desconocidos. Egipto tendrá miles de escritores, pero el que ha capturado nuestra imaginación es Naguib Mahfouz y otros que, como él, le hablan al lector qua miembro de la raza humana, no como a socio de un club exclusivo, demarcado, en este caso, por la nación. Soy cósmico, tántrico, y no me da vergüenza reconocerlo. Mi tendencia como escritor será siempre trascender las coordenadas de lo fortuito, o ¿quién de nosotros ha elegido su sexo, su patria, su color y, a veces, su credo? Mi oposición era sencilla: escribir de manera que me pudiera dar a entender al mayor número de personas posible, desarrollando temas con los que la mayor cantidad posible de personas pudiera relacionarse. ¿Qué temas son esos? Las reacciones humanas fundamentales: el horror, la maravilla, el terror místico, la intriga y el suspenso. No escribiría de jíbaros, ni de chamacos de caserío, ni de ser puertorriqueño o marginado, a menos que fueran componentes literarios de un proyecto artístico que tuviera como intención primordial alcanzar uno de los efectos que he listado. Nunca estarían en mi literatura de gratis, porque sí, como pasa muchas veces con los escritores comprometidos, cuyos textos se convierten en pasarelas de estereotipos y situaciones trilladas, de estampas. Pero ese debate con Mayra surgió de un malentendido puramente lingüístico. Al final estábamos hablando de lo mismo, pero usando palabras distintas. Ella se refería a no copiar las formas occidentales, la idea "universalista” dictada por Occidente, y yo a no abusar de nuestros lenguajes privados ni de caer en lo folclórico. Pero aún así, prefiero pecar de lo primero, que de lo segundo. Rememorando ahora ese dilema, me da un poco de apuro, por lo ridículo y passé del tópico, incluso en ese entonces.

NR: Háblame de Aire, aquel suplemento que dirigiste por corto tiempo en las páginas del semanario puertorriqueño Claridad.

PC: Aire fue una idea del poeta Marcos Pérez Ramírez, al que me une una amistad entrañable. Él tenía los contactos; hicimos la propuesta a Peri Coss, que en aquel momento 
era el director, y nos pusieron a trabajar yo creo que ese mismo día. Nuestra jefa inmediata era Graciela Rodríguez Martinó. La idea era hacer una separata literaria, convocando a todos los escritores jóvenes del país. Cuatro páginas nos dieron. Fue hermoso. Nosotros mismos armábamos el diseño, que el gráfico Pablo García pacientemente montaba. Siempre metíamos grabados antiguos de monstruos perturbadores, viñetas renacentistas pornográficas (una vez nos censuraron un fauno erecto que hostigaba a una ninfa), y otras cosas muy raras, muy psicodélicas. Teníamos 18 años. Publicamos mis cuentos y los poemas de Marcos. Luego empezaron a llegar textos de otros escritores jóvenes, muy buenos, muy en sintonía con lo que estábamos haciendo, nunca un panfleto, nunca estupideces patrióticas o redencionistas y, considerando que se trataba de Claridad, eso fue un milagro. Nos llegaron hasta cuentos de ciencia ficción. Yo me sentía en la gloria. Además, me había enamorado perdidamente de la periodista Sofía Ortiz. Un día nos llegó un cuento extrañísimo, muy bien escrito. Era un muchacho mayor que nosotros, Juan López Bauzá, que hoy día es una de las figuras literarias de importancia en Puerto Rico. Fueron días muy agitados y hermosos. Estuvimos ahí cuando Filiberto Ojeda ${ }^{3}$ dejó tirado su localizador en las escaleras del periódico, su último escape. Conocimos a escritores de Cuba que nos mandaban sus cuentos y poemas y propias separatas y revistas. Nuestro asombro: todos estábamos en lo mismo, rompiendo la misma cadena y ensayando los primeros pasos de una literatura completamente distinta.

NR: Sé que vives en República Dominicana desde hace seis años, ¿qué ha significado para tu proceso creativo ese distanciamiento geográfico?

PC: Lazos matrimoniales me llevaron a ese país tan genial, en donde viven mis dos hijos geniales. Entiendo esa pregunta, pero voy a tener que desilusionarte: ya yo me sentía muy distanciado de los procesos en Puerto Rico mientras vivía en la isla. De esa manera, vivir en la República Dominicana significó para mí un acercamiento, más bien. Un acercamiento a la realidad del Caribe. Como puertorriqueños residentes en un país subsidiado somos a veces incapaces de reconocer, mucho menos entender, la realidad económica, política, social y cultural de nuestros vecinos caribeños. Geográficamente vivimos en el Caribe, pero mentalmente habitamos una especie de burbuja mágica, impenetrable. Vivir en la República Dominicana me puso en contacto con otras fuentes, muy ricas, que tuvieron un efecto sensibilizador y enriquecedor; la religiosidad popular, el panteón caribeño, la farmacopea de las islas, las pequeñas y medianas empresas, el cooperativismo urbano y rural, las juntas de vecinos, el contrabando y la piratería, la astucia del hambre, las complejidades de la identidad racial, el dinamismo de los creoles, la potencia indiscutible de la brujería, la pobreza extrema y, lo más importante de todo, la inquebrantable alegría. Y no digo que en Puerto Rico no sea posible sentir la fuerza de estas cosas, pero tenemos que admitir que, en general, han sido o están siendo ahogadas por un estilo de vida consumista, artificial y desconectado, y todo eso combinado con un chauvinismo narcisista y patriotero que es, en muchos sentidos, también un artículo de consumo. Viviendo en la República Dominicana I'm keeping it real, como quien dice... En la República Dominicana he encontrado muchos temas, pero sobre todo, se me han

${ }^{3}$ Filiberto Ojeda Ríos, líder independentista y fundador del Ejército Popular Boricua (los “macheteros”) en 1976. Vivió en la clandestinidad por quince años, hasta que fuera asesinado por agentes del FBI el 23 de septiembre de 2005. 
ocurrido nuevas formas de entender y narrar lo que se vive en Puerto Rico. Con la distancia, las cosas que yo sentía embarradas por la artificialidad del discurso redencionista y chauvinista, ahora están limpias. Lo local ha sido liberado del exceso de significados que le impuso generación tras generación de escritores e intelectuales mesiánicos. Que es lo mismo que decir que las palabras para designar ciertas cosas dejaron de ser símbolos para ser sólo palabras.

NR: De tu primera colección de cuentos Historias tremendas (San Juan: Isla Negra, 1999), la crítica académica y periodística ha destacado su marcado carácter lúdico, la fina ironía, el recurso de la parodia de múltiples géneros y el virtuosismo en el manejo de la lengua literaria. El crítico Juan Duchesne Winter incluso postuló la posibilidad de hallar en estos relatos la presencia de un sujeto no representado en la literatura puertorriqueña: el ciudadano insano, suerte de espectro comprometido sólo con el quiebre de los paradigmas de la moral social.

PC: Durante muchos años me preocupó excesivamente la forma. Esa era una fuente de ansiedad para mí. Elegir la palabra correcta y formular la oración perfecta llegaron a convertirse en tareas que, efectivamente, me paralizaban. Por eso tardé tanto tiempo en publicar mi primer libro. Algunos han dicho que mi prosa es virtuosista, otros, que manierista, pero la palabra que buscan es obsesiva y maniática. Esas dos palabras son las que mejor describen mi idioma literario. Con el tiempo, ese anal retentiveness me está abandonando y puedo escribir con mayor agilidad. Creo que esa liberación se la debo al año y medio que trabajé en la revista Rumbo y en el periódico Diario Libre. ${ }^{4}$ Había que escribir bien y entregar los escritos a tiempo. Aprendí que la mayoría de las veces la elegancia de la prosa le resta fuerza al cuento, le quita belleza o genialidad. Actualmente me muevo hacia una prosa más orgánica, más torpe... En cuanto al sujeto que ha descubierto Duchesne, creo que es afín al que podríamos encontrar en las novelas de Rushdie, de Pynchon o de Murakami. Un sujeto que se ve involucrado en, o es partícipe de, situaciones que son desabridas sólo en la superficie, pero que constantemente saltan de órbita, como electrones, y revelan dimensiones sórdidas o fantásticas en personajes falsamente ordinarios. Un hombre debe terminar con su novia, pues de manera impredecible se ha puesto a poner huevos. ¿Se trata de un lenguaje figurado? ¿Huevo en el sentido caribeño de "meter la pata" o huevo en el sentido literal? No importa, al final todos los huevos empollan y sus "hijos" escapan al mundo, destrozando su casa. O si no, un enamorado escribe a una columna del corazón. Su cursilería es fabulosa, pero su problema, su dilema y su fisonomía, atroces. ¿Cómo le dirá este enamorado valentino a su amada que debe espolvorearse talco insecticida en su pelaje porque sus pulgas lo están acabando? La disyuntiva es esa, pero el punchline es otro, y es obvio: ¿qué criaturas son éstas?

NR: En el prólogo de tu libro más reciente, Historias atroces (San Juan: Isla Negra, 2003), mencionas que en este volumen complementario de Historias tremendas "el leit motiv es la traslación, tanto en su acepción de "movimiento" como en el de "traducción”, y que los relatos que lo integran se definen más bien "por una peregrinación o rutina al cabo de la cual sobreviene una revelación de carácter importante”.

${ }^{4}$ Rumbo y Diario Libre son publicaciones dominicanas. La primera salió del mercado en el año 2004. 
PC: Me arrepiento mil veces y maldigo el día en que cometí esa novatada de tratar de explicar mis narraciones. ¿Y no funciona así toda la narrativa habida y por haber? Los personajes progresan, superando etapas, haciéndose gradualmente más fuertes (o débiles), acercándose cada vez más una meta, que es al mismo tiempo una revelación y una explicación de sus trabajos. Clásico mito del héroe, no importa cuántas variaciones incluyamos. En "Fin de un amor imposible”, Magali pasa de ser una huérfana desamparada a ser una bruja de cuidado, muy perspicaz, con un novio lobo o perro. Su madre ha muerto y le envía cartas desde el infierno; su padre ha sido secuestrado por extraterrestres. Un secreto terrible existe, pero el narrador lo que quiere contar es lo que pasó la noche en que Magali y su amante cuadrúpedo terminaron su relación. Los vericuetos de la historia, no obstante, acaban por aclarar todo el panorama. El amante sólo cree ser un perro; es un adolescente feral, criado por perros. Magali reflexiona que una madre que abandona a su hijo en la selva no merece sino el infierno... La relación que los une es prohibida no por bestial, sino por incestuosa. Como gesto de despedida, el muchacho se levanta con trabajo sobre sus piernas y trata de articular el nombre de su hermana/esposa, pero sólo le sale un balbuceo que confirma su terrible identidad: Mowgli, el niño salvaje del Libro de la selva.

NR: En Historias atroces incursionas en la ciencia ficción, género prácticamente desconocido en la historia literaria puertorriqueña.

PC: Soy un científico frustrado... Corrección: soy un científico loco mal encaminado. Las matemáticas se me opusieron, y no sabes cuánto las admiro. En fin, que para mí la ciencia es un manantial de inspiración. Desde muy pequeño quise entender los descubrimientos científicos más relevantes de la historia, curiosidad que nunca me ha abandonado. De tal modo, hoy manejo a fondo los detalles generales de la teoría de la relatividad, del Standard Model de la física cuántica, la teoría del Big Bang, la teoría inflacionaria, la teoría del Big Crunch, la radiación cósmica de fondo... Sé cómo funciona una estrella y también por qué los científicos están desesperados ante esa misteriosa sustancia que compone el $74 \%$ del universo visible. Nadie sabe qué es, pero todos saben que está ahí. El funcionamiento del universo siempre ha sido para mí una fuente constante de asombro. Mi padre alimentaba esa curiosidad porque él mismo se ataranta delante de esos misterios. Todavía hoy me llama a veces escandalizado por una nueva noticia acerca de las distancias que nos separan de las galaxias más lejanas...Y no son sólo los problemas de la física. ¿Tú sabías que las mitocondrias que todos tenemos en las células eran originalmente parásitos? Son animales distintos de nosotros, con los que hemos establecido una relación de simbiosis. La bióloga Lynn Margulis, cuyo primer esposo fue Carl Sagan, ha propuesto que incluso las formas de vida más avanzadas surgen del acoplamiento de organismos diferentes. Las posibilidades literarias son infinitas: nuestro hígado, nuestro bazo, ¿fueron anteriormente, hace millones de años, animales independientes? Sé que exagero y malinterpreto la teoría, pero de eso se trata; se trata de una excusa. Es el caso de las teorías de la complejidad espontánea, que también me dejan boquiabierto, se me ocurren inmediatamente infinidad de posibles argumentos. Irónicamente, el asombro que me invade cuando considero algunos temas científicos es un asombro místico, es un temor numinoso. Mis cuentos de ciencia ficción casi siempre llevan ese derrotero... En Puerto Rico la ciencia ficción fue un género inexistente hasta la publicación de Historias atroces. 
En los setenta se publicó en la isla una novela titulada Los Garadiávolos, pero había sido escrita por un filipino llamado Alfredo García Garamendi. Era una novela que combinaba el vodú con la intriga noir y el thriller de extraterrestres. Una locura pulp, iy qué ilustraciones! Sé que México sí tiene un historial relativamente extenso de literatura de ciencia ficción, aunque esas piezas están, más bien, organizadas en antologías y manuales temáticos. Los autores no son muy conocidos como cultivadores de ciencia ficción, no abundan esos libros en las librerías. Bioy Casares incursionó en el género más de cuatro veces ("El calamar opta por su tinta", "La trama celeste”, La invención de Morel, "Los afanes" y otros que habré olvidado), y Borges dos ("Tlön, Uqbar, Orbis Tertius” y "There Are More Things"). Para nosotros los caribeños, la ciencia ficción es una mina riquísima e inexplorada. Al presente finalizo un volumen de cuentos de ciencia ficción titulado El quinto punto cardinal, con más de 25 narraciones, una de las cuales, “El hábito hace al monje”, fue finalista del Premio Terra Ignota de Ciencia Ficción.

NR: Hay un cuento de Historias atroces, el titulado "Relato del piloto que dijo adiós con la mano", en que pareces alejarte del escrúpulo desterritorializador de tus textos anteriores para entrar de lleno en el tema de la identidad puertorriqueña. Lo interesante de este gesto es que entras en esta materia a través de una reinterpretación del traspaso imperial de Puerto Rico como una colonización no sólo de la cultura, sino del cuerpo mismo del puertorriqueño.

PC: Ese cuento tiene un origen muy extraño; lo soñé exactamente como se lee. Fue como si me hubiera sentado en una sala de cine y hubiera empezado la función. Vi cómo se desenvolvía la trama, cómo aparecían nuevos personajes, cómo la protagonista, Inés, traicionaba vilmente al sargento Jeffries. Tienes razón, este cuento es uno de los pocos que contextualiza la acción en la isla. Pero fíjate que lo que hago con una mano lo desbarato con los pies. Todo ocurre en algún bosque de San Lorenzo, ${ }^{5}$ a principios de siglo, pero en lugar del típico cuento del costumbrismo jíbaro, el locus amoenus ha sido suplantado por un bohío de dos pisos, habitado por campesinos lúgubres y una adolescente misteriosa. El paisaje forestal no es hospitalario, pues, como pronto descubrirá Jeffries, meteorólogo del ejército estadounidense de ocupación, está inundado de extraños seres uniformados con escafandras de sobrevivencia, y no se sabe si su procedencia es interestelar o diabólica. Lo que sí podemos constatar es que realizan inescrutables mediciones a los cientos de jóvenes campesinas que voluntariamente acuden todas las noches. ¿Para qué? Eso lo sabemos al final. ¿Se trata de una metáfora de la identidad? A lo mejor; después de todo, cuando el sargento Jeffries se despide, nunca sabemos si la actitud de Inés es la actitud inocente de un clon, de un simulacro sintético, o si se trata, real y efectivamente, de Inés. Por otro lado, tanto en ese cuento como en el que le sigue, "Tres episodios con caballos," trabajo mucho el tema de la raza, del género y las relaciones de poder. La "herencia” es una idea muy presente en ambos, el legado de un trauma irresoluto, el presente como una repetición fantasmal, mise-en-abyme, del pasado.

NR: Tras la publicación de la novela gráfica Ánima Sola, con la cual te inicias en el género del cómic, ¿podemos esperar algo más en esa dirección?

${ }^{5}$ El municipio puertorriqueño de San Lorenzo está ubicado en el extremo este de la cordillera central. 
PC: Tengo escritos varios episodios más del Ánima Sola, pero también tengo listos un par de títulos muy distintos, menos fantásticos, más crudos y, al mismo tiempo, más tiernos, más manga. Mi contacto con los cómics sucedió muy al principio, en mi infancia, con los personajes de Marvel y DC. Esto no quiere decir que no haya sido, y sea, un fanático del kitsch mexicano: yo era fijo con Kalimán y Fantomas. Más adelante me cautivó el fino trabajo de Alberto Breccia y el libretista Héctor Oesterheld con los títulos Mort Cinder, El Doctor Morgue, El Eternauta y Sherlock Time. Soy también un fanático de Moebius, de Milo Manara, del trabajo de Morvan y Buchet, de Schuiten, el arquitecto belga, de Robert Crumb. Mi trabajo como libretista de novela gráfica comparte el ethos de esta amalgama... Sin embargo, los proyectos que actualmente acaparan más mi tiempo tienen que ver con el cine. No me cabe en la cabeza por qué el Caribe tiene un cine tan malo... ¡Y no me vengas a hablar del cine cubano! Overrated. El Caribe debería tener el mejor cine del mundo. Nuestro cine es malo porque entre nosotros hemos subestimado el papel del engranaje más importante de una producción cinematográfica: el escritor, el guionista. Gran parte del cine caribeño está escrito por comediantes de shows vespertinos, por carajos con el dinero suficiente, por saltapatrases bien conectados o por directores engreídos que creen que si saben dirigir también saben escribir. Es absurdo. Michel Gondry tuvo la siguiente idea: ¿qué tal si un día recibiéramos en nuestro buzón una tarjeta que dijera "Usted ha sido borrado de la memoria de fulana"? Esta es, realmente, una idea fabulosa. Cualquiera se da cuenta. ¿Qué hizo Gondry, uno de los mejores directores hoy día? Llamó a Charlie Kaufman, le contó la idea y lo puso a trabajar. ¿Por qué? Porque Gondry es un gran director y un tipo inteligente que sabe que Kaufman es un gran escritor. Resultado: una de las mejores y más bellas películas de los últimos cinco años, Eternal Sunshine of the Spotless Mind. Esa conciencia fundamental de que una buena película comienza con una buena historia, con un buen guión, nos resulta completamente incomprensible. Pero eso también va a cambiar. 